\title{
Structure and Mechanical Behavior of Bulk Nanocrystalline Materials
}

\author{
J.R. Weertman, D. Farkas, K. Hemker, \\ H. Kung, M. Mayo, R. Mitra, and \\ $H$. Van Swygenhoven
}

The reduction of grain size to the nanometer range $(\sim 2-100 \mathrm{~nm})$ has led to many interesting materials properties, including those involving mechanical behavior. In the case of metals, the HallPetch equation, which relates the yield stress to the inverse square root of the grain size, predicts great increases in strength with grain refinement. ${ }^{1,2}$ On the other hand, theory indicates that the high volume fraction of interfacial regions leads to increased deformation by grain-boundary sliding in metals with grain size in the low end of the nanocrystalline range. ${ }^{3}$ Nanocrystalline ceramics also have desirable properties. Chief among these are lower sintering temperatures and enhanced strain to failure. These two properties acting in combination allow for some unique applications, such as low-temperature diffusion bonding (the direct joining of ceramics to each other using moderate temperatures and pressures). Mechanical properties sometimes are affected by the fact that ceramics in a fine-grained form are stable in a different (usually higher pressure) phase than that which is considered "normal" for the ceramic. ${ }^{4-9}$ To the extent that the mechanical properties of a ceramic are dependent on its crystallographic structure, these differences will become evident at the smaller size scales.

\section{Models and Simulations of Mechanical Behavior}

It is uncertain how deformation takes place in very fine-grained nanocrystalline materials. It has been recognized for some time that the Hall-Petch relationship, which usually is explained on the basis of dislocation pileups at grain boundaries, must break down at grain sizes such that a grain cannot support a pileup. ${ }^{10}$ Even some of the basic assumptions of dislocation theory may no longer be appropriate in this size regime. ${ }^{11} \mathrm{Re}$ cently considerable progress has been made in simulating the behavior of extremely fine-grained metals under stress using molecular-dynamics techniques. ${ }^{12-18}$ Molecular-dynamics (MD) simulations of deformation in nanophase $\mathrm{Ni}$ and $\mathrm{Cu}$ were carried out in the temperature range of $300-500 \mathrm{~K}$, at constant applied uniaxial tensile stresses between $0.05 \mathrm{GPa}$ and $1.5 \mathrm{GPa}$, on samples with average grain sizes ranging from $3.4 \mathrm{~nm}$ to $12 \mathrm{~nm}^{14}$ Each sample contained at least 15 grains, that is, between $10^{5}$ and $1.2 \times 10^{6}$ atoms. A second moment tightbinding potential ${ }^{19}$ with constant temperature and constant pressure ${ }^{20}$ was used together with periodic boundary conditions. Nickel and copper were chosen for the simulations because $\mathrm{Ni}$ is a face-centered-cubic (fcc) metal with a rather high stacking-fault energy, whereas $\mathrm{Cu}$ has a low value. Extensive databases on microstructure and mechanical properties exist for both metals.

Since the nature of the misorientation of grains across a boundary in real nanophase samples may vary from random to textured orientations, ${ }^{21,22}$ two procedures were used to create the samples: a stochastic Voronoi construction and a constrained stochastic Voronoi construction in which the grain misorientations are restricted to between $3^{\circ}$ and $17^{\circ},{ }^{13,23}$ These are denoted as high-angle (HA) and lowangle (LA) samples. They were then annealed at $300 \mathrm{~K}$ giving a final density above $97 \%$ of that of a perfect crystal, the exact value depending on the grain size. (The density shortfall arises from the high volume fraction of slightly lower density grain boundaries.) The characterization of the microstructure was done by calculating atomic energy, coordination number, and local crystalline order in terms of a bond analysis technique. ${ }^{24}$ This technique allowed a distinction to be made between fcc and hexagonal-close-packed (hcp) atoms, the latter being the stacking faults in an fcc matrix. Analysis of the microstructure showed that whereas the mean energy per atom in an LA and an HA sample is approximately the same for a given mean grain size, the HA sample has most of its excess energy in the grain boundaries, while in the LA sample the energy is distributed between the boundaries and the interiors of the grains as elastic distortions.

Uniaxial deformation at the smallest loads reveals that Young's modulus equals the value for a polycrystalline material when the grain size is $10 \mathrm{~nm}$ or higher. At smaller grain sizes a gradual reduction in modulus is found with decreasing grain size, up to $25 \%$ in an $\mathrm{HA}$ sample with a mean grain size of $3.4 \mathrm{~nm}$. At higher loads, following a transient period after the load is applied, the strain increases linearly with time for all grain sizes. ${ }^{15,16,25}$ Figure 1 shows the strain rate versus the inverse of the grain size for the $\mathrm{Ni}$ and $\mathrm{Cu}$ simulated samples. The computed strain rates are high compared with actual experimental values, but for these small sample sizes (10-25 $\mathrm{nm}$ ) any relative velocity is still four orders of magnitude smaller than the velocity of sound. At the smallest grain sizes explored $(<8 \mathrm{~nm})$ the strain rate for a given applied stress increases with decreasing grain size. This behavior indicates that the Hall-Petch slope is negative at these very fine grain sizes. At larger grain sizes the strain rate is rather insensitive to grain size. An energy balance indicates that at the smallest grain sizes 
studied, the total a mount of grain boundary remains constant during deformation. ${ }^{15,16}$ These observations suggest an important characteristic of plasticity in nanophase metals under the present conditions: there is no damage accumulation during deformation, similar to the case of superplasticity. The deformation mechanism for grain sizes below $8 \mathrm{~nm}$ can be described in terms of a model based on grain-boundary viscosity controlled by a self-diffusion mechanism at the disor- dered interface activated by thermal energy and stress. ${ }^{14,16}$ Calculations of the activation energy give a value comparable to the migration energy for self-diffusion. Slices through several deformed HA samples show an increase in the number of small hcp planes in the grain boundaries with increasing deformation. Figure 2 depicts a slice of an HA sample with $5.2 \mathrm{~nm}$ average grain size (a) before and (b) after deformation. Small hep clusters grow into planes during deformation,

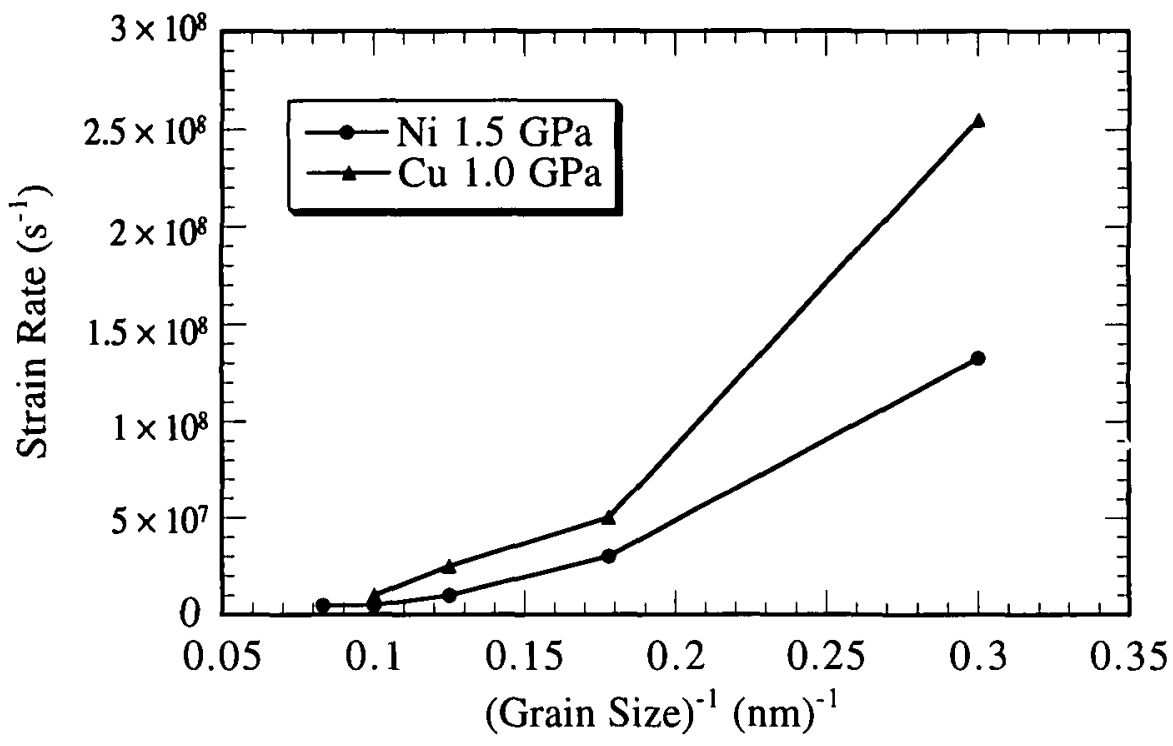

Figure 1. Strain rate versus inverse grain size for Cu deformed with $1.0 \mathrm{GPa}$ and $\mathrm{Ni}$ with $1.5 \mathrm{GPa}$.
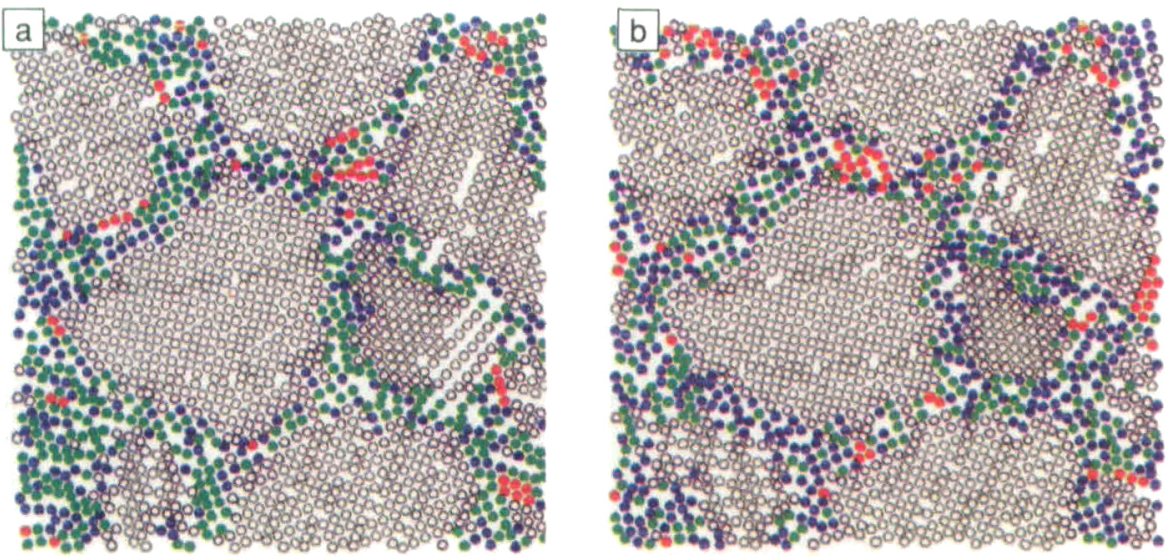

Figure 2. Section of 5.2-nm grain-size Cu sample with (HA) grain boundaries (a) before and (b) after $3 \%$ deformation. (Orange circles are hexagonal-closepacked [hcp] atoms; green circles are other 12-coordinated atoms; blue circles are non-12-coordinated atoms; and open circles are face-centered-cubic [fcc] atoms. Hexagonal-close-packed clusters grow but remain in the grain boundaries.)

but remain in the grain boundaries. Only when much larger loads are applied are stacking faults observed in the grain interiors. At larger grain sizes fewer hcp planes are observed at a given deformation time and under a similar load. The deformation level is much less. These observations indicate a transition to another deformation mechanism, probably one based on dislocations. Nevertheless, significant dislocation activity has not been seen in the simulations, even in the $12-\mathrm{nm}$ HA samples. However in the textured (LA) samples, where the larger degree of coherence in the interfaces helps transfer the shear component of the applied stress into the grain interior, clear motion of partial edge dislocations is observed, even in the 5.2-nm samples. The 3D CAVE at Virginia Tech is a powerful instrument for locating and identifying dislocations; measuring their Burgers vectors; characterizing the nature of stacking faults; and following the process by which partial dislocations are created at the boundary, travel across the grain, and are annihilated at the facing boundary. Figure 3 shows three pictures taken in the CAVE at different moments of deformation of a 5.2-nm textured (LA) Ni sample. For clarity the fcc atoms have been removed, the grain-boundary atoms have been colored blue, and the hcp atoms red. In the upper right-hand corner of Figure $3 a$, a small hcp cluster can be observed in the grain interior. Figures $3 b$ and $3 c$ show a partial dislocation and associated stacking fault arising from the cluster and moving out into the grain interior.

In summary, the computer simulations show that at very small grain sizes intergranular deformation mechanisms supplant intragranular mechanisms. The large volume fraction of grain boundaries leads to a softening of the material. The competition depends not only on the grain size but also on the grain-boundary type.

\section{Structure of Actual Nanocrystalline Material}

While most models of nanocrystalline material describe the mechanical behavior of material that is free of defects (other than the grain boundaries), actual samples are likely to contain pores, flaws, trapped gases, other impurities, and/or a wide distribution of grain sizes. In the case of nanocrystalline metals made by inert-gas condensation, ${ }^{26}$ small-angle neutron scattering has shown that most of the $1-5 \%$ density shortfall arises from the presence of small pores. ${ }^{27}$ (The grain sizes of these samples were large enough that the influence of the less-dense grain boundaries on the overall density was 

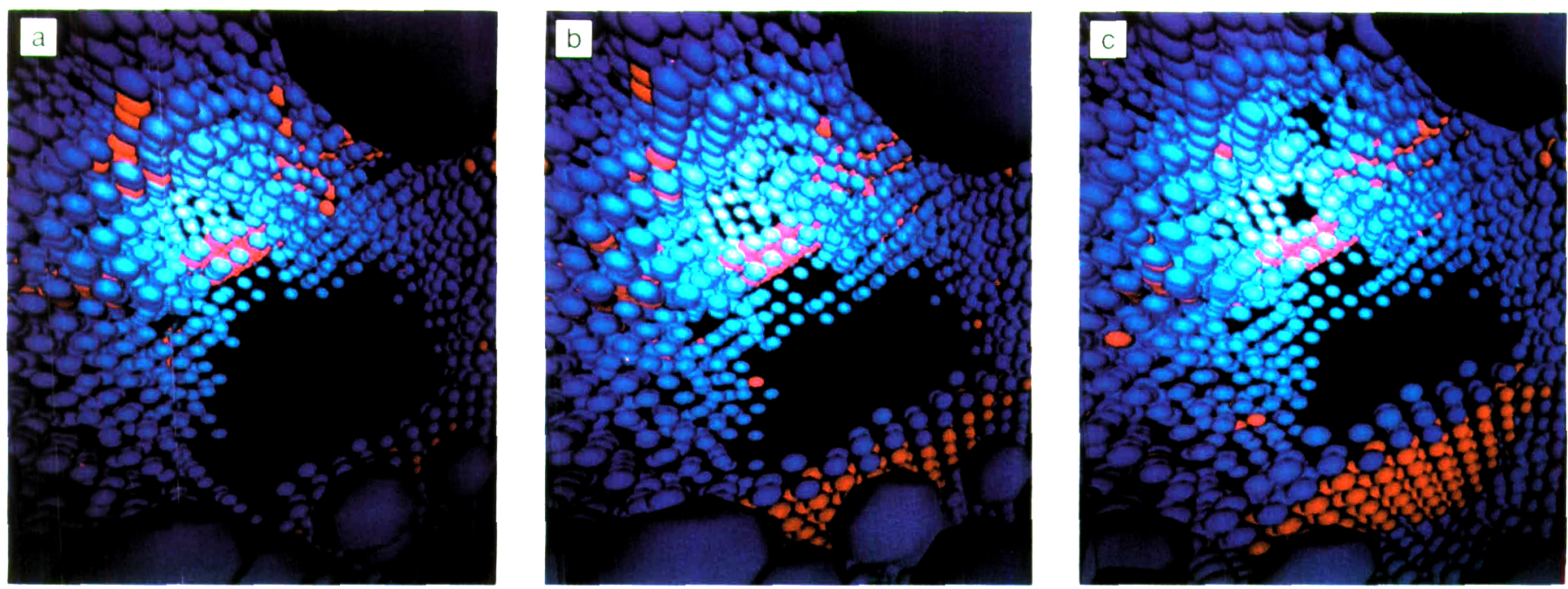

Figure 3. A stacking fault attached to a partial dislocation (upper right corner) in (a) moves toward the grain interior in (b) and (c). The sample in this simulation is 5.2-nm textured low-angle (LA) Ni. (Red and blue spheres are hexagonal-close-packed [hcp] and grain-boundary atoms, respectively, while empty space indicates the face-centered-cubic [fcc] atoms that were removed for clarity.)

small.) Pore size scales with grain size. These pores are stabilized by gas trapped during processing. ${ }^{28}$ Larger flaws caused by imperfect bonding of powder particles cause samples to fail in tension at stresses well below failure stresses in compression. $^{28-30}$

The average grain size of a nanocrystalline metal sample usually is obtained from $x$-ray line broadening experiments, and this value together with the corresponding hardness or yield strength is used in the construction of a Hall-Petch plot. Such plots are then compared with theoretical predictions to gain insight into deformation mechanisms. However describing a nanocrystalline structure by a single grain size may be inappropriate. Figure 4 shows a size distribution in a nanocrystalline $\mathrm{Cu}$ sample, as measured by transmission electron microscopy (TEM). The sizes refer to coherently scattering regions, that is, the size of the individual twins in this heavily twinned material. Each data point represents the relative number of coherent regions with the given size, and the solid curve is a fit of these data points to a log normal distribution. The dotted curve is a conversion of this number density curve to a volume-fraction distribution. The grain size, measured by $x$-ray diffraction and analyzed using the Warren-Averbach method, ${ }^{31}$ is $22 \mathrm{~nm}$, which is close to the peak value of the number density curve. It is evident that describing this sample on a Hall-Petch plot as representing mechanical behavior at $22 \mathrm{~nm}$ is question- able. Representing the structure by the size of the twinned regions was chosen because this is a size more appropriate for determining dislocation behavior. The nanocrystalline samples contain an appreciable fraction of special bounda- ries. While $\Sigma 3$ twins are the most common, other special orientation relations are present. Figure 5 shows $\Sigma 3$ twins and a $\Sigma 19$ boundary in nanocrystalline $\mathrm{Cu}$. The frequent occurrence of special boundaries across grains impacts the operation

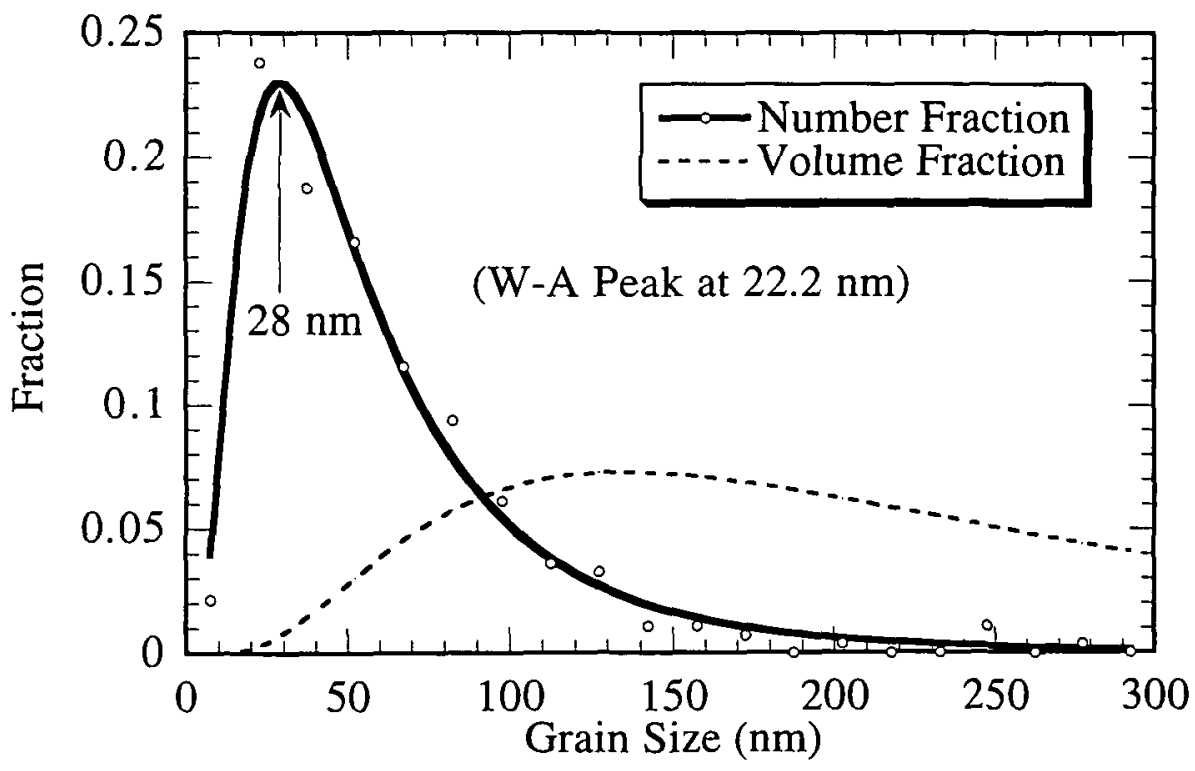

Figure 4. Size distributions of the individual twins in a nanocrystalline Cu sample made by inert-gas condensation and compaction. Data points are relative numbers of twins in a given size range. The solid curve is a fit of a log normal distribution to the data points; the dotted curve is a conversion of this number-fraction curve to a volume-fraction curve. Warren-Averbach $(W-A)$ analysis of $x$-ray diffraction data gives a grain size of $22 \mathrm{~nm}$. 
of deformation mechanisms dependent on grain-boundary diffusion. ${ }^{3}$

From the beginning of nanocrystalline research in ceramics, much of the work has suffered from the difficulty of making specimens that are both fully dense and large enough to make traditional measurements. The problem is related to compaction. In order to obtain a homogeneously packed powder compact that will sinter well, sufficient pressure must be exerted to allow particle rearrangement within the compact. Because a tremendous number of particles per unit volume exist when the particles are of nanometer size, the frictional resistance to sliding associated with the many interparticle contacts is considerable. In addition, nanoceramic powders typically contain hard agglomerates (strongly bonded clumps of crystallites) that need to be broken before substantial particle arrangement can occur. The final result is that $1-9 \mathrm{GPa}$ of pressure is required to prepare samples that can attain full density and nanocrystalline grain size. ${ }^{32-35}$ This pressure translates into a sample size about $1 \mathrm{~cm}$ in diameter (limited by the force capability of the press) by about 1-2-mm thick (limited by the buildup of residual stresses within the compact). As a consequence of the sample size limitations, much of the work in nanocrystalline ceramics, and in particular much of the early work, was plagued by samples that were not fully dense. Porous samples then (not surprisingly) gave rise to such observations as abnormally low elastic moduli and low hardness in nanocrystalline ceramics. ${ }^{36,37}$ Fast diffusivities were measured in porous specimens because the porosity allowed "bulk" diffusion to occur via fast surface routes along the many internal and interconnected pore surfaces. ${ }^{38}$ Porosity then is a parameter to be consistently considered when evaluating data from nanocrystalline ceramics. The same caveat applies in the case of nanocrystalline metals, although densities in the 98-99\% of the theoretical value now are frequently obtained.

\section{Mechanical Behavior of Actual Nanocrystalline Material}

Many, if not most, studies of the mechanical behavior of nanocrystalline metals have provided data that are largely a reflection of the influence of sample imperfections. Early work seemed to indicate that the elastic modulus of nanocrystalline metals is far below that of coarse-grain equivalents. ${ }^{39,40}$ However later measurements using improved measuring techniques on nearly fully
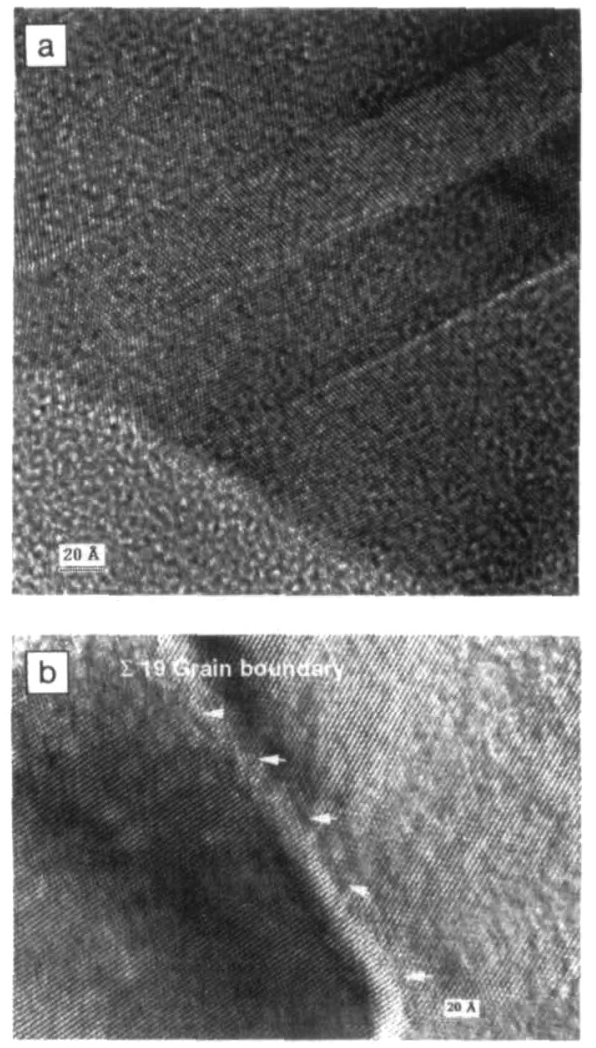

Figure 5. Transmission-electronmicroscopy picture showing (a) \3 twins and (b) a $\Sigma 19$ boundary in a nanocrystalline Cu sample. The arrows in (b) indicate secondary grain-boundary dislocations with Burgers vector $b=(1 / 38)\langle 116\rangle$.

dense samples showed that Young's modulus is little changed from the literature value, at least down to the grain sizes measured. ${ }^{29,41}$ Results of MD simulations predict that the grain size must fall below $10 \mathrm{~nm}$ for substantial shortfalls in the modulus to be seen. ${ }^{14,18}$ It is difficult to make high-quality samples with such small grain size. Because nanocrystalline samples usually are very small, most studies of their plastic properties have been limited to microhardness measurements. Here too the sample quality has had a strong effect on the hardness values. As can be seen from Figure 6 in Reference 30, hardness values in nanocrystalline $\mathrm{Cu}$ increased by about a factor of two as the quality of the samples improved. The overall trend in both older and newer sets of data is an increase in hardness as the grain size in the samples drops. However stress-strain curves on small tensile samples ("mini" samples) cut from the $9-\mathrm{mm}$ as- compacted disks show little change of yield stress with grain refinement (Figure 6 a). ${ }^{30}$ It is believed that processing flaws cause brittle fracture in this strong material in which dislocation activity, which normally would blunt the cracks and increase fracture toughness, is hindered or suppressed. In order to decrease the probability of finding such a flaw in a specimen, tensile testing has been performed with unique instrumentation at Johns Hopkins University that permits stress-strain curves to be taken on "micro" samples with a gauge length of only $300 \mu \mathrm{m}$ and cross section of $200 \times$ $200 \mu \mathrm{m} .{ }^{42}$ (The gauge section is approximately the size of Lincoln's bow tie on a penny.) The results of tests on nanocrystalline $\mathrm{Cu}$ and $\mathrm{Ni}$ are shown in Figures $6 \mathrm{~b}-\mathrm{d}$. The tensile yield stress of the nanocrystalline $\mathrm{Cu}$ sample increased by about $1 / 3$ as the volume of the gauge section dropped by a factor of 250 . Similar results were found on another $\mathrm{Cu}$ sample that was tested in both the mini and micro systems. The nanocrystalline $\mathrm{Ni}$ sample deformed almost entirely elastically. TEM examination showed that the Cu sample contained many more large grains than the $\mathrm{Ni}$ sample, which remained mostly nanocrystalline. Evidence of dislocation activity was seen in the large grains in the $\mathrm{Cu}$. This activity probably contributed to the limited plastic deformation noted in the $\mathrm{Cu}$, whereas the Ni deformation was primarily limited to elastic strains. Note the high tensile strength values for both the pure $\mathrm{Cu}$ and $\mathrm{Ni}$. To mitigate the effect of flaws, stress-strain curves were generated in compression. It can be seen that the $\mathrm{Ni}$ still undergoes only elastic deformation, finally breaking at over $2 \mathrm{GPa}$ (Figure $6 \mathrm{~d}$ ). This value is within about an order of magnitude of the theoretical shear strength for $\mathrm{Ni}$. The compressive yield strengths for $\mathrm{Cu}$ are shown on the HallPetch plot of Figure 6a. These yield strengths are consistent with the hardness results $(1 / 3$ the Vickers hardness is a rough measure of the yield strength) and lie close to the line extrapolated from coarse-grain data. Figure $6 a$ hints at a decrease in the slope of the Hall-Petch relation at the smallest grain sizes measured. The turndown in slope may indeed be real, but it also may have resulted from poorer quality of these samples, which could not be warm-compacted because of grain growth problems. It is interesting to note that the hardness and compressive yield strengths appear to lie on smooth curves using the nominal grain size determined from Warren-Averbach analysis of $x$-ray line broadening measure- 

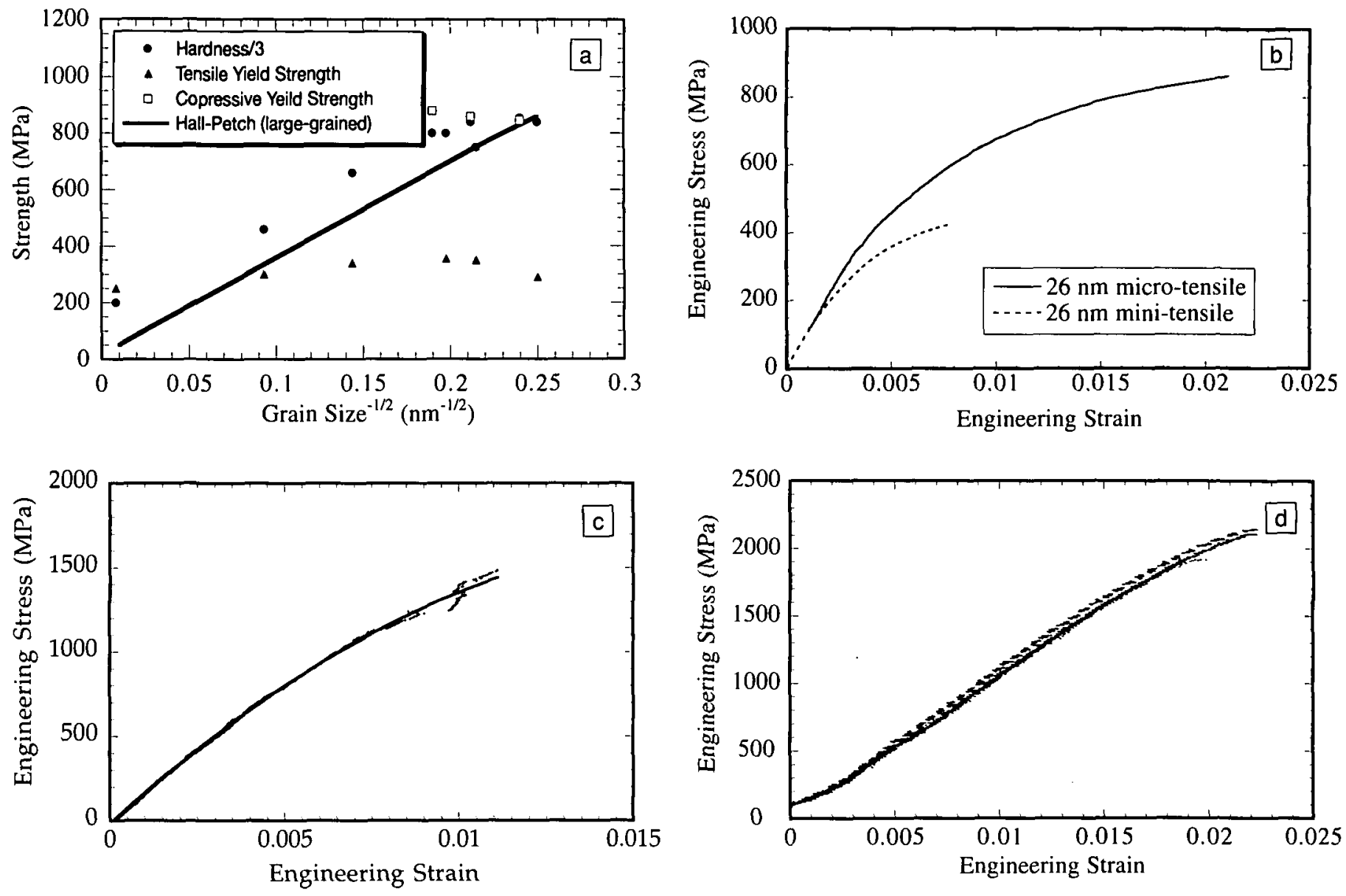

Figure 6. (a) Hall-Petch plot for nanocrystalline $\mathrm{Cu}$. Tensile tests done on "mini" samples. The solid line is extrapolation from coarse-grain results; (b) tensile stress-strain curves for nanocrystalline Cu with nominal grain size of $26 \mathrm{~nm}$, showing comparison of results from a "mini" sample and a "micro" sample cut from the same disk; (c) tensile stress-strain curve for "micro" sample of nanocrystalline Ni, nominal grain size $28 \mathrm{~nm}$; (d) compression curves for three Ni samples, nominal grain size of $21 \mathrm{~nm}$. See text for explanation of the terms "mini" and "micro".

ments, yet data such as seen in Figure 4 show that the internal structure cannot be characterized by a single grain size.

The two greatest advantages currently offered by nanocrystalline ceramics over conventional ceramics are their lower sintering temperatures and enhanced strain to failure. For example, in the case of titania, an approximately $600^{\circ} \mathrm{C}$ reduction in sintering temperature can be obtained by using nanopowders. However it is important to note that this reduction depends much more on the size of the agglomerates in the powder than in the size of the crystallites. ${ }^{4-45}$ Powders composed of large agglomerates sinter poorly, despite the nanometer scale of the individual crystallites or grains within the agglomerates. Nevertheless, if agglomeration can be avoided, the potential for low-temperature sintering is significant. This feature may allow nanoceramics to be co-processed with metals in ways heretofore unrealized and also may significantly reduce the energy costs typically associated with ceramic processing.

The second major advantage of nanocrystalline ceramics is the extended strain to failure. This phenomenon, welldocumented in submicrometer-grained oxide ceramics, allows these normally brittle materials to exhibit enormous ductility under conditions of moderate stress and temperature. ${ }^{46-48}$ Deformation takes place completely in the solid state, and elongations to failure typically are in the range of $100-800 \%$, a significant improvement over the usual $0-2 \%$. The primary requirement for this superplasticlike behavior is a fine $(<1-2 \mu \mathrm{m})$ grain size. Given that nanocrystalline ceramics have an even finer grain size than submicrometer-grained ceramics, it is not surprising that they exhibit even larger strains to failure. The phenomenological equation for superplastic flow suggests that nanocrystalline ceramics should deform at faster rates, lower stresses, and lower temperatures than their largegrained counterparts. ${ }^{49}$ These predictions have all been borne out in practice. Figure 7a shows the acceleration in strain rates that takes place upon a fourfold reduction in grain size in yttria-stabilized zirconia. ${ }^{50}$ Another similar reduction in grain size would put this material in the interesting position of deformation at stresses and strain rates typically used for commercial superplastic forming of metals. Lower temperature deformation also was observed. Note the approximately $300^{\circ} \mathrm{C}$ drop in superplastic forming temperature for $40-\mathrm{nm}$ titania, as compared to titania with $1-\mu \mathrm{m}$ grain size (Figure $7 \mathrm{~b}) .^{51,52}$ The forming temperature for nanocrystalline titania (the ceramic) is actually about $250^{\circ} \mathrm{C}$ below that for commercial superplastic titanium (the metal), although the stresses 

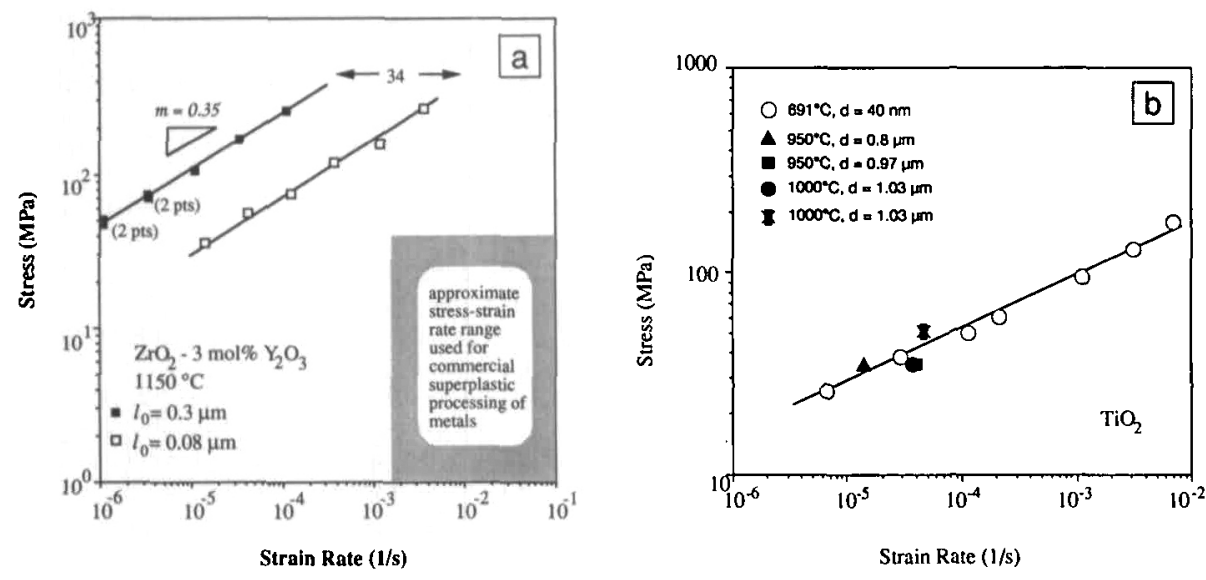

Figure 7. (a) The fourfold smaller grain size of the nanocrystalline yttria-stabilized zirconia leads to a factor of 34 increase in strain rate at the same stress and temperature ${ }^{50}(\mathrm{~b})$ nanocrystalline rutile $\left(\mathrm{TiO}_{2}\right)$ achieves the same forming rates under comparable stresses as micrometer-grained rutile, but at $250-300^{\circ} \mathrm{C}$ lower temperatures. $^{51,52}$

are higher.

It should be noted that most of the data currently available on the stress-strain behavior of nanocrystalline ceramics is from small compression specimens. ${ }^{50,51,53,54}$ Tensile behavior has yet to be quantified. (As a result, strictly speaking, the large strains observed in these materials do not fit the definition of superplasticity, which must occur in tension.) Large-scale applications of nanocrystalline "superplasticity," such as bulk near-net-shape forming from solid nanocrystalline ceramic stock, still await suitably sized pieces. However these size limitations have not dampened the enthusiasm for exploiting nanocrystalline superplasticity in other arenas. Two applications-oriented uses of superplasticity are diffusion bonding and sinterforging. In diffusion bonding, two ceramic parts are pressed together at moderate temperatures and pressures to form a seamless bond through diffusion and grain growth across the interface. The large deformations help this process by providing perfect mating: the surface roughness of one part is accommodated by the flow of the mating part to fill the interstices. As Figure 8 shows, such bonds are more easily made in nanocrystalline ceramics than in larger grained ceramics, due to both the enhanced plastic flow of the former and the greater number of grain boundaries nanocrystalline ceramics provide for diffusional flux across the interface. ${ }^{55}$ Recently Ferkel and Riehemann ${ }^{56}$ have shown that excellent diffu- sion bonds can also be achieved using a well-compacted interlayer of nanocrystalline powder between the pieces to be joined. Sinter-forging is a second applica-
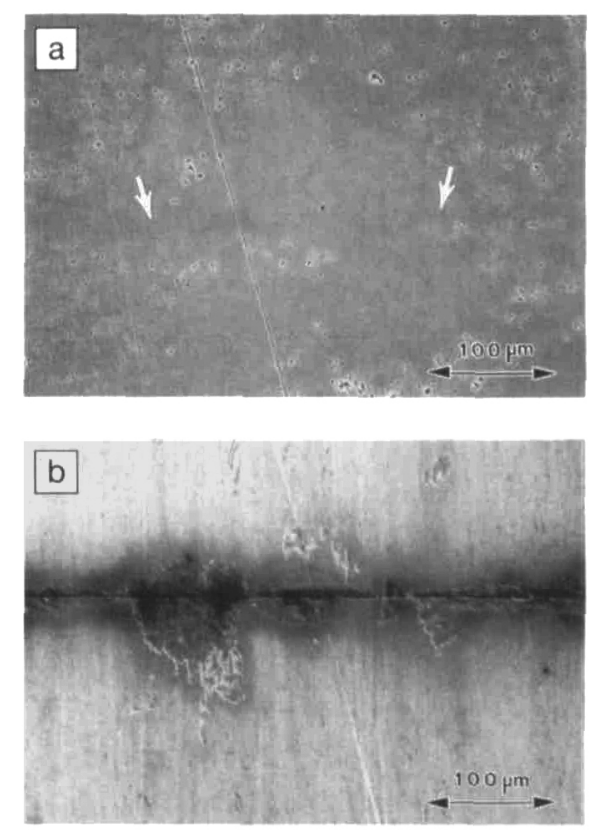

Figure 8. (a) Nanocrystalline and (b) submicrometer-grained blocks of $3 Y-T Z P$ joined together by diffusion bonding at $1090^{\circ} \mathrm{C}$ under $10-\mathrm{MPa}$ pressure. Arrows point to joint location on the nanocrystalline sample. ${ }^{55}$ tion for the extensive plastic flow in nanocrystalline ceramics, and one which is gaining visibility because it solves one of the material's major problems: poor sintering behavior associated with the (typically) high levels of agglomeration. The large, "unsinterable" pores in ceramic bodies can be filled in by internal superplastic flow of the surrounding matrix under the right conditions of temperature, strain rate, and so on. Technically the operation differs from hot pressing only in that a closed die is not used. The results can be impressive. Large pores that do not disappear after six hours (and more) in pressureless sintering vanish completely in the first few minutes of sinter-forging. ${ }^{44,49}$

\section{Conclusions}

The prospects of exceptionally high strengths in nanocrystalline metals and large ductility in nanocrystalline ceramics are strong drivers to bring about the necessary improvements in synthesis and processing. While considerable progress has been made, much work remains to be done in order to gain an understanding of deformation mechanisms in the fascinating grain-size range of -3-15 $\mathrm{nm}$.

\section{References}

1. E.O. Hall, Proc. Phys. Soc. London, Sect. B 64 (1951) p. 747.

2. N.J. Petch, I. Iron Steel linst. 174 (1953) p. 25.

3. R.L. Coble, J. Appl. Phys. 34 (1963) p. 1679.

4. R.C. Garvie, J. Phys. Chem. 69 (1965) p. 1238.

5. W. Winterer, R. Nitsche, S.A.T. Redfern, W.W. Schmahl, and H. Hahn, Nanostruc. Mater. 5 (1995) p. 679.

6. O. Yamaguchi, M.Shirai, and M. Yoshinaka, I. Am. Ceram. Soc. 71 (1988) p. C510.

7. H-Y. Lee, W. Riehemann, and B.L. Mordike, J. Eur. Ceram. Soc. 10 (1992) p. 245.

8. G. Skandan, Nanostruc. Mater. 5 (1995) p. 111.

9. G. Skandan, C.M. Foster, H. Frase, M.N. Ali, J.C. Parker, and H. Hahn, ibid. 1 (1992) p. 313.

10. T.G. Nieh and J. Wadsworth, Scripta Metall. Mater. 25 (1991) p. 955.

11. R.O. Scattergood and C.C. Koch, ibit. 27 (1992) p. 1195.

12. H. Van Swygenhoven, M. Spaczer, and $A$. Caro, Nanostruc. Mater. 10 (1998) p. 819.

13. Ibid., in Microscopic Simulation of Interfacial Phenomena in Solids and Liquids, edited by S.R. Phillpot, P.D. Bristowe, D.G. Stroud, and J.R. Smith (Mater. Res. Soc. Symp. Proc. 492, Warrendale, PA, 1998) p. 29.

14. H. Van Swygenhoven, M. Spaczer, D. Farkas, and A.Caro, Nanostruc. Mater. in press. 15. H. Van Swygenhoven and A. Caro, Appl. Phys. Lett. 71 (1997) p. 12.

16. Ibid. (unpublished manuscript).

17. J. Schiøtz, F.D. DiTolla, and K.W. Jacobsen, Nature 391 (1998) p. 561. 
18. J. Schiøtz, T. Vegge, F.D. DiTolla, and K.W. Jacobsen, in Modelling of Structure and Mechanics of Materials from Microscale to Product, edited by J.V. Carstensen, T. Leffers, T. Lorentzen, O.B. Pedersen, B.F. Serensen, and G. Winther (RISØ National Laboratory, Roskilde, Denmark, 1998) p. 133.

19. F. Cleri and V. Rosato, Phys. Rev. B 48 (1993) p. 48.

20. M. Parrinello and A. Rahman, J. Appl. Phys. 52 (1981) p. 12.

21. P.G. Sanders, M. Rittner, E. Kiedaisch, J.R. Weertman, H. Kung, and Y-C. Lu, Nanostruc. Mater. 9 (1997) p. 433.

22. O.V. Mishin, V.J. Gertsman, R.Z. Valiev, and G. Gottstein, Scripta Mater. 35 (1996) p. 873.

23. G.Z. Voronoi, Reine Angew. Math. 134 (1908) p. 199.

24. D.J. Honeycutt and H.C. Anderson, J. Phys. Chem. 91 (1987) p. 4950.

25. H. Van Swygenhoven, M. Spaczer, and A. Caro (unpublished manuscript).

26. H. Gleiter, Prog. Mater. Sci. 32 (1989) p. 223. 27. P.G. Sanders, J.A. Eastman, and J.R. Weertman, Actn Mater. 46 (1998) p. 4195.

28. S.R. Agnew, B.R. Elliott, C.J. Youngdahl, K.J. Hemker, and J.R. Weertman, in Modelling of Structure and Mechanics of Materials from Microscale to Product, edited by J.V. Carstensen, T. Leffers, T. Lorentzen, O.B. Pedersen, B.F. Sørensen, and G. Winther (RISØ National Laboratory, Roskilde, Denmark, 1998) p. 1.
29. P.G. Sanders, J.A. Eastman, and J.R. Weertman, Acta Mater. 45 (1997) p. 4019.

30. P.G. Sanders, C.J. Youngdahl, and J.R. Weertman, Mater. Sci. Eng. A 234-236 (1997) p. 77.

31. B.E. Warren, X-ray Diffraction (Dover, New York, 1990).

32. R.W. Siegel, S. Ramasamy, H. Hahn, Z. Zonghuan, and L. Ting, J. Mater. Res. 3 (1988) p. 1367.

33. H. Hahn, J. Logas, and R.S. Averback, ibid. 5 (1990) p. 609.

34. A. Pechenik, G.J. Piermarini, and S.C. Danforth, J. Am. Ceram. Soc. 75 (1992) p. 3283.

35. R.A. Andrievski, Int. J. Powder Metall. 30 (1994) p. 59.

36. M.J. Mayo, R.W. Siegel, A. Narayanasamy, and W.D. Nix, J. Mater. Res. 5 (1990) p. 1073.

37. M.J. Mayo, R.W. Siegel, Y.X. Liao, and W.D. Nix, ibid. 7 (1992) p. 973.

38. H.J. Höfler, H. Hahn, and R.S. Averback, Defect Diff. For um 75 (1991) p. 195.

39. D. Korn, A. Morsch, R. Birringer, W. Arnold, and H. Gleiter, J. de Phys. C5 (1988) p. 769. 40. G.W. Nieman, J.R. Weertman, and R.W. Siegel, J. Mater. Res. 6 (1991) p. 1012.

41. T.D. Shen, C.C. Koch, T.Y. Tsui, and G.M. Pharr, ibid. 10 (1995) p. 2892.

42. W.N. Sharpe, Jr. and R.O. Fowler, ASTM STP 1204 (American Society for Testing and Materials, Philidelphia, 1993) p. 386.

43. M.F. Yan and W.W. Rhodes, Mater. Sci. Eng. 61 (1983) p. 59.
44. D.C. Hague, M.S. thesis, The Pennsylvania State University, 1992.

45. E.A. Barringer, R. Brook, and H.K Bowen, in Sintering and Heterogeneous Catalysis, edited by G.C. Kuczynski, A.E. Miller, and G.A. Sargent (Plenum Press, New York, 1984) p. 1. 46. T.G. Nieh, C.M. McNally, and J. Wadsworth, J. Met. (1989) p. 31.

47. Y. Maehara and T.G. Langdon, J. Mater. Sci. 25 (1990) p. 2275.

48. T.G. Nieh, J. Wadsworth, and F. Wakai, Int. Mater. Rev. 36 (1991) p. 146.

49. M.J. Mayo, Nanostruc. Mater. 9 (1997) p. 717 50. M. Çiftçioglu and M.J. Mayo, in Superplasticity in Metals, Ceramics, and Intermetallics edited by M.J. Mayo, M. Kobayashi, and J. Wadsworth (Mater. Res. Soc. Symp. Proc. 196, Pittsburgh, 1990) p. 77.

51. H. Hahn and R.S. Averback, J. Am. Ceram Soc. 74 (1991) p. 2918.

52. C. Carry and A. Mocellin, Ceram. Int. 13 (1987) p. 89.

53. G.B. Prabhu and D.L. Bourell, Scriptn Metall. Mater. 33 (1995) p. 761.

54. M.J. Mayo, in Superplasticity in Advanced Materials, edited by S. Hori, M. Tokizane, and N. Furushiro (Japan Society for Research on Superplasticity, Osaka, 1991) p. 541.

55. T.H. Cross and M.J. Mayo, Nanostruc. Mater. 3 (1994) p. 163.

56. H. Ferkel and W. Riehemann, ibid. 7 (1996) p. 835 .

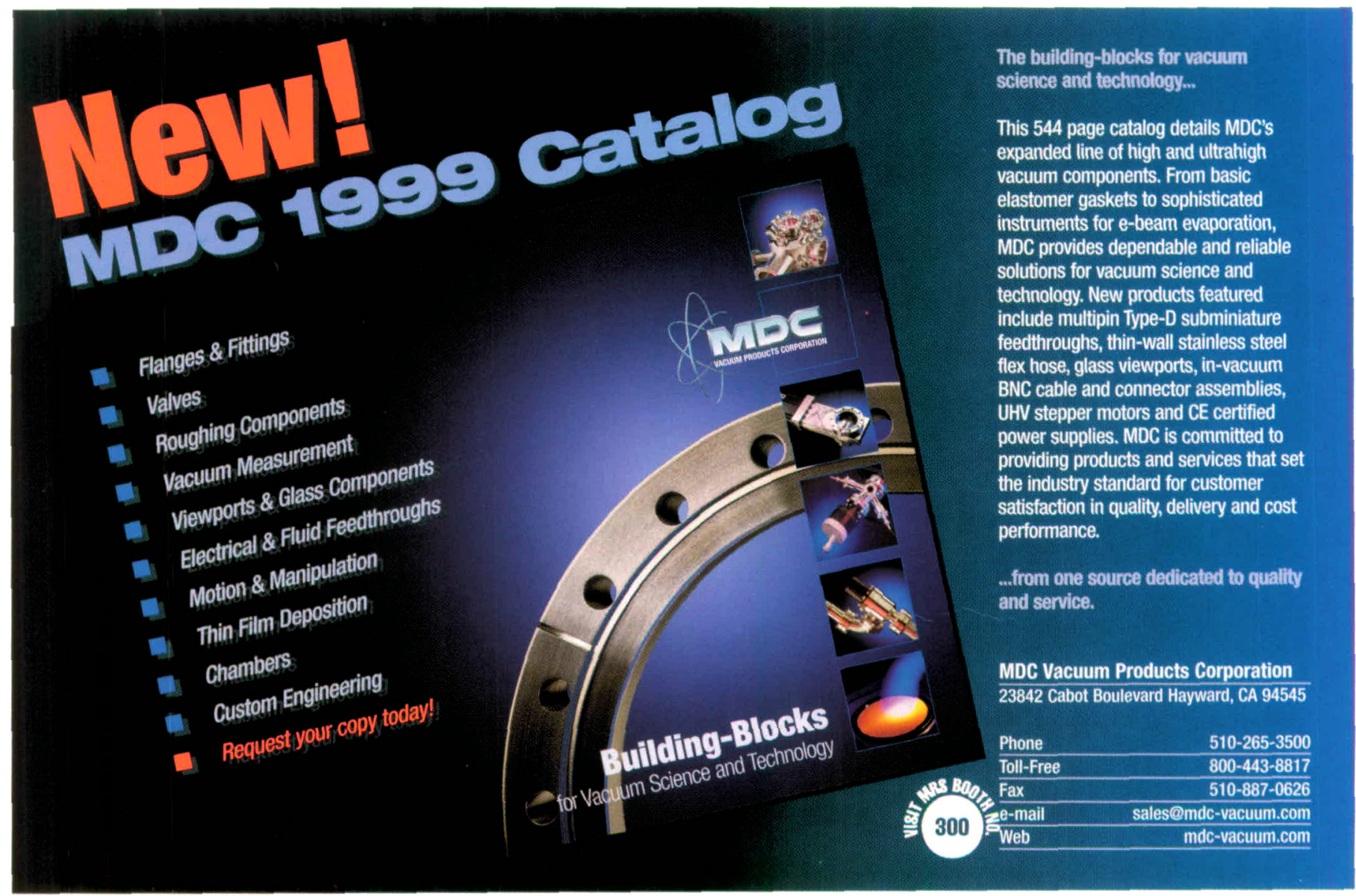




\section{offers the hroadest,}

\section{most completeline}

of Scanning Probe

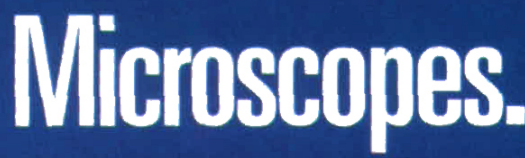

No every application. That's why ThermoMicroscopes ${ }^{\text {Tt }}$ offers a wide range of scanning probe microscopes (SPM). And that's the reason we developed our line of application-specific SPM systems.

Take our Polymer System, ${ }^{\prime 2}$ for example. It includes the awardwinning Explorer"'AFM that lets you scan in the full continuum of both contact and non-contact scanning modes. No need to depend on one mode that doesn't work with soft samples, or one that is certain to result in probe damage when you scan very hard samples. You select the scanning mode that's best for each of your applications.

Along with Explorer, the Polymer System includes the Pulsed Force Mode imaging accessory for measuring adhesion and compliance; a $\mu \mathrm{TA} \mathrm{A}^{\mathrm{m}}$ imaging accessory for mapping thermal conductivity as well as measuring local thermal and mechanical properties with a hot/cold stage for temperature-dependent studies; application-specific software; and much, much more. In other words, you get everything you need to help you find answers to many of the most challenging polymer research questions.

And the Polymer System is just one example of our SPM systems. ThermoMicroscopes SPMs are used in a wide range of research applications by respected scientists in Fortune $500 \mathrm{com}$ panies, universities and government laboratories throughout the world. They're proven performers backed by the world's largest instrument manufacturer.

So, whether you're considering your first or your tenth AFM, check out ThermoMicroscopes. Compare our performance, service, price and results. You'll see why our instruments offer The Difference You Can Measure."

Circle No. 14 on Reader Service Card.

VIUTHERMOMICROSCOPES
¿IS Park Scientific Instruments TOPOMETRIX

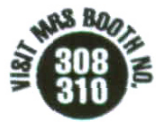

1171 Borregas Avehue, Sunnyvale, CA 94089 USA Telephone 408.747.1600 Fax 408.747.1601 Email info@ thermomicro.com www.thermomicro.com

1938 by ThermoMicroscopes. "ThermoMicroscopes," "Polymer Systems", "Explorer", and "The Difference You Can Measure" are trademarks of ThermoMicroscopes. Other products or brand names are trademarks or registered trademarks of their respective holders. "Puised Force Mode" is a product of WiTac Gmbh. 


\section{GET CONNECTED}

\section{BENEFITS OF MEMBERSHIP}

\section{Two Annual MRS Meetings}

As an MRS member, you'll automatically receive the Call for Papers and Program for upcoming meetings, as well as discounted MRS Meeting registration rates.

\section{MRS Bulletin}

The MRS Bulletin is your free monthly publication with timely news and features on the research and development of advanced materials.

\section{Journal of Materials Research}

Yours for a very low member rate, Journal of Materials Research is an international archival journal encompassing physical, chemical, and engineering research on advanced materials and processing techniques.

\section{MRS Books \& Videotapes}

As an MRS member, you may purchase MRS books and videotapes at 15-30\% below list price. You'll also enjoy reduced rates for journals and books from other scientific publishers.

\section{Opportunities to Connect}

- Career services for members include the Job Center at MRS Spring and Fall Meetings.

- The annual Membership Directory is your connection to over 12,400 MRS members worldwide.

- Reduced membership renewal and meeting fees are available to unemployed or retired members, as well as recent graduates as yet unemployed.
The strength of MRS continues to be its membersand its ability to link its members - with connections in academia, industry, and government.

Get connected to the MRS interdisciplinary scientific community. Submit your membership application today!

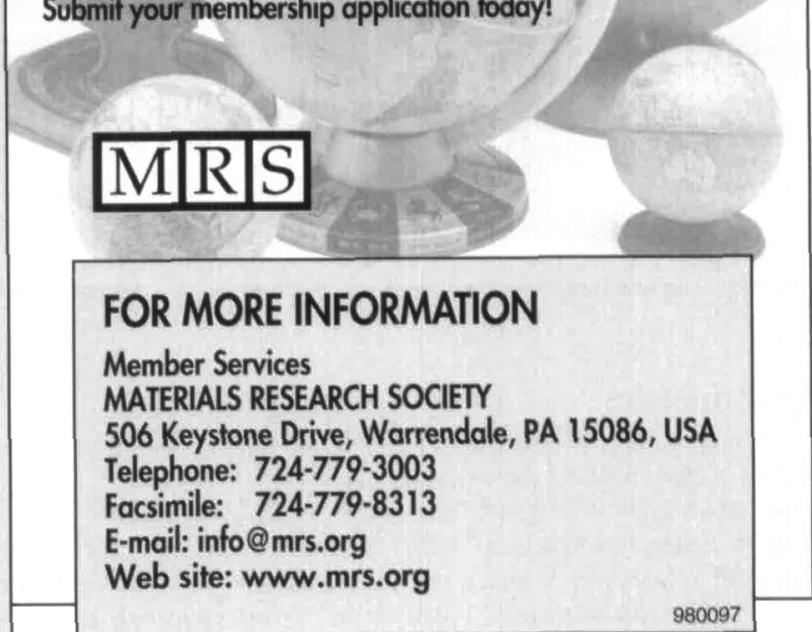

\section{Standard Vacuum Components}

\section{For Your Application}

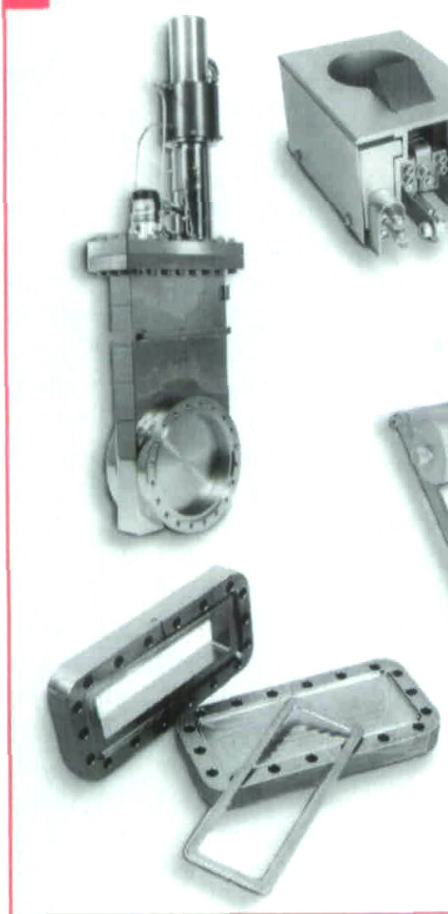

Thermionics offers a full line of vacuum components from ion pumps to xyz manipulators. What sets us apart from other companies is our ability to listen to and understand your specific vacuum requirements.

Whether you need a thermocouple gauge tube or a complete system, our engineers will ensure that you get exactly what you need.
For your free copy of our 340-page catalog, contact

\section{0 thermionics vocuum products}

231-B Otto Street

Port Townsend, WA 98368

Toll-free: (800) 962-2310

Fax: $\quad(360)$ 385-6617

Intemet: www.thermionics.com Email: sales@thermionics.com

Circle No. 13 on Reader Service Card. 